Editorial for JACl-P - September $7^{\text {th }} 2016$

\title{
Common Variable Immunodeficiency Disorders (CVID) - diagnoses of exclusion, especially combined immune defects
}

Professor Helen Chapel

University of Oxford,

Level 7, Oxford University Hospitals

Headley Way, Oxford, OX3 9DU, UK

1 Diagnostic criteria for the various heterogeneous conditions that make up

2 Common Variable Immunodeficiency Disorders (CVID) are important for

3 individual patient's diagnosis, prognosis and treatment, as well as for

4 immunological research. Patients and their doctors need a precise diagnosis

5 that relates to prognosis and therefore to appropriate treatment. Whilst those

6 with a Combined Immune Deficiency (CID) might benefit from stem cell

7 transplantation to correct both the $\mathrm{T}$ cell defect as well as the B cell

8 deficiency, those patients with pure antibody failure do well with

9 immunoglobulin replacement alone. Thus the definition of CVID has great

10 clinical importance, although it remains a diagnosis of exclusion and this has

11 led to the term being used as a reason for replacement therapy rather than

12 purely for diagnostic reasons in some countries.

14 Several attempts to refine the original 1999 ESID-PAGID definition(1) have been made in the last 15 years. The most recent by the panel of the International Consensus document (ICON) on CVIDs (2). This supports the previous suggestion, from the French group, to exclude those patients with low numbers of circulating $T$ cells who have a type of CID, namely Late Onset Combined Immune Deficiency (LOCID). In addition, the ICON recommends

20 that flow cytometry to enumerate T, B and NK cells is essential to identify

21 those forms of CID that present as antibody failure but should no longer be considered within the CVID group.

The International Union of Immunological Societies (IUIS) PID committee emphasize the heterogeneous nature of CVID by ensuring that the newly described single gene defects in primary antibody failure syndromes be 
named after the gene in which the mutation is disease-causing (such as ICOS or CD19). They also define CVIDs as plural(3) and include LOCID as a distinct condition separate from CVID in the IUIS PID Classification.(4) This has encouraged the development of data for additional exclusion criteria for a diagnosis of CVID, as by Bertinchamp et al. in this issue(5).

The data in Bertinchamp et al. comes from the well-recognized and reliable DEFI database. The objective was to compare three different CVID definitions (ESID/PAGID 1999, ESID 2014, DEFI 2015) using data from 521 patients with a diagnosis of primary hypogammaglobulinaemia. Using the ESID/PAGID 1999 definition, 351 patients were classified as CVID. The 2014 ESID definition excluded $18 \%$ of patients, most of them with less severe disease, whilst $10 \%$ had a major T-cell defect. Given the French authors previous publication relating to LOCID, Bertinchamp et al. propose that opportunistic infections or very low naïve CD4+ $T$ cell counts should also exclude patients from a diagnosis of CVID. Using these criteria, 62 patients of the initial CVID population did not meet the new diagnostic criteria; it was notable that these patients accounted for $77 \%$ of the deaths within a 5 -year period; these patients also represented the $12 \%$ with consanguinity. The authors conclude that opportunistic infections or very low naïve CD4 T cells define a separate group and that these patients warrant specific genetic studies in view of their

In regard to prognosis, it is now 8 years since the Northern European database showed that the clinical phenotypes of CVID patients could be divided by disease-related complications and these phenotypes correlated with survival(6). The divisions, into infection-free or particular disease-related clinical phenotypes, were confirmed with further data from France and the US (7). In contrast, attempts so far to define prognosis by B cell immunophenotyping alone have been disappointing. Hence the need to find genetic and other markers, as well as $T$ cell numbers, that might indicate prognosis. 
60 There have been many genetic studies in patients meeting the original criteria

61 for CVID. However identification of disease genes for monogenic forms explains only a very small percentage (2-10\%) of patients who turn out to

63 have a disease-causing mutation in a single, non-redundant, gene. Such 64 patients often have a family history and a T cell defect, though the T cell deficiency may not be apparent initially. Other findings in patients initially diagnosed as having CVID have included mutations in TACI, CTLA-4, PIK3CD and many others(8), but these have been reported in healthy individuals too, suggesting that these are susceptibility genes that contribute to but are not solely responsible for primary antibody failure, the common feature of all CVID patients. Even ARTEMIS, a gene in which a defect was associated with a monogenic form of Severe Combined Immune Deficiency (SCID), has clinical phenotypes that range from SCID to antibody failure(9).

Researchers need homogeneous groups of patients for laboratory, and especially, genetic studies. Ensuring that CIDs are clearly distinguished from primary antibody failures in which T cells are normal, influences the choice of appropriate investigation between a candidate gene panel, exome or even whole genome sequencing. Exome sequencing is profitable for defining those with a CID(10) and WGS has led to the identification of a number of immune pathways that may be defective in patients with sporadic CVID(11). Other experimental strategies need to be considered for exploring the several pathways that contribute to sporadic CVIDs.

Evidence for polygenicity in sporadic, late onset CVIDs, is accumulating. Late onset of disease, lack of a positive family history, phenotypic variation as well as the finding of genetic variants in healthy family members and in the general population, add to the suggestion that several/many genetic variants will be involved in both the primary antibody failure component and in the diseaserelated complications of CVID(11). The evidence so far is laid out in two excellent reviews $(8,12)$. The role of susceptibility and modifier genes as well as environmental factors and somatic mutations(13), in both CVIDs and other

92 forms of immune deficiency syndromes need to be explored further in patients with well-defined clinical as well as immunological phenotypes. 
The other important point in Bertinchamp et al. is that of the remaining 244 patients meeting the stricter criteria, only $18(7 \%)$ patients were aged below 15 years at diagnosis. The importance of an appropriate diagnosis in those presenting in childhood cannot be over-emphasized. In the study from Philadelphia, of the children diagnosed with CVID, about half had diseaserelated complications as well as lower T cells(14); the authors commented that "the pediatric CVID population may warrant more aggressive intervention because of their potential for a longer disease duration and higher disease burden." A high proportion, if not most, of this group are likely to represent CIDs rather than sporadic, non-famililal, antibody failure.

105

Basing a CVID diagnosis on measuring serum immunoglobulin levels, antibody responses and flow cytometry is now relatively straightforward and clinical factors contributing to the clinical phenotype, such as unusual infections or complications, must also be taken into consideration and documented carefully. Given differences in the diagnostic criteria versus research and database purposes, Bertinchamp et al. is instructive. The authors point out the differences between patients with a family history of immune deficiency and sporadic cases, the importance of excluding those with mild T cell defects or unexplained opportunistic infections and probably those presenting in childhood.

Word 1,162

117 1. Conley ME, Notarangelo LD, Etzioni A. Diagnostic criteria for primary 118 immunodeficiencies. Representing PAGID (Pan-American Group for 119 Immunodeficiency) and ESID (European Society for Immunodeficiencies).

120 Clin Immunol. 1999 Dec;93(3):190-7.

121 2. Bonilla F, Barlan, I., Chapel, H., Costa-Carvalho, BT., Cunningham122 Rundles, C., de la Morena, T. Espinosa-Rosales, FJ., Hammarström, L., 123 Nonoyama, S., Quinti, I., Routes, JM., Tang, LMK., Warnatz,K. J Allergy Clin 124 Immunol Pract 2016;4:38-59. 
3. Al-Herz W, Bousfiha A, Casanova j-I, Chapel H, Conley ME,

Cunningham-Rundles $\mathrm{C}$, et al. Primary Immunodeficiency Diseases: an update on the Classification from the International Union of Immunological

128 Societies Expert Committee for Primary Immunodeficiency. Frontiers in Immunology. [Review]. 2011 2011-November-8;2:1-26. 4. Al-Herz W, Bousfiha, A., Casanova, JL., Chatila, T., Conley, ME,M Cunningham-Rundles, C., Etzioni, A., Franco, JL., Gaspar, H., Holland, SM., Klein, C., Nonoyama, S., Ochs, HD., Oksenhendler, E., Picard C., Puck, JM., Sullivan, K., Tang, MLK. Primary immunodeficiency diseases: an update on the classification from the International Union of Immunological Societies Expert Committee for Primary Immunodeficiency. Frontiers in Immunology. 2014;5:1-33.

137 5. Bertinchamp R, Gérard, L., Boutboul, D., Malphettes, M., Fieschi, C., 138 Oksenhendler, E. for the DEFI study group. Exclusion of patients with a 139 severe T-cell defect improves the definition of Common Variable Immunodeficiency. JACI in Practice. 2016.

142 Grimbacher,B., Fieschi, C., Thon V., Abedi, MR., Hammarstrom,L. Common 143 variable immunodeficiency disorders: division into distinct clinical phenotypes. 144 Blood. 2008;112:277-86.

1457 Chapel H, Lucas, M., Patel, S., Lee, M., Cunningham-Rundles, C., 146 Resnick, E., Gerard, L., Oksenhendler, E. Confirmation and improvement of 147 criteria for clinical phenotyping in common variable immunodeficiency 148 disorders in replicate cohorts.

149 . J Allergy Clin Immunol 2012 130:1197-8.

150 8. Bogaert D, Dullaers, M., Lambrecht, BN., Vermaelen,KY., De Baere, 151 E., Haerynck,F. . Genes associated with common variable immunodeficiency: 152 one diagnosis to rule them all? J Med Genet 2016;Published Online First: 1 153 June 2016 doi:10.1136/jmedgenet- 2015-103690:1-16.

154 9. Volk T, Pannicke, U., Reisli, I., Bulashevska, A., Ritter, J., Björkman, 155 A., Schäffer, AA., Fliegauf, M., Sayar, EH., Salzer, U., Fisch, P., Pfeifer, D., Di

157 Güner, SÜ., Schindler, D., Hammarström, L., Rizzi,M., Hummel, M., Pan- 
Hammarström, Q., Schwarz, K., Grimbacher, B. DCLRE1C (ARTEMIS) mutations causing phenotypes ranging from atypical severe combined immunodeficiency to mere antibody deficiency. . Hum Mol Genet 2015;24:7361-72.

10. Maffucci P, Filion, CA., Boisson, B., Itan, Y., Shang, L., Casanova, JL.,

163 Cunningham-Rundles C. Genetic Diagnosis Using Whole Exome Sequencing

164 in Common Variable Immunodeficiency. Front Immunol. 2016 7:doi:

165 10.3389/fimmu.2016.00220.

166 11. van Schouwenburg P, Davenport, E.E., Kienzler, A.K., Marwah, I.,

167 Wright, B., Lucas, M., , Malinauskas T, Martin, H.C., W.G.S.

168 Consortium,Lockstone, H.E., Cazier, J.B., Chapel,H.M., Knight,J.C., Patel

169 S.Y. Application of whole genome and RNA sequencing to investigate the 170 genomic landscape of common variable immunodeficiency disorders,. Clinical 171 immunology, . 2015;160:301-14.

172 12. Li J, Wei, Z.,Li, YR., Melkorka Maggadottir, SM., Chang, X., Desai, A., 173 Hakonarson, $\mathrm{H}$. . Understanding the genetic and epigenetic basis of common 174 variable immunodeficiency disorder through omics approaches. BBA 175 General SubjecTS. 2016: doi: 10.1016/j.bbagen.2016.06.014.

176 13. Rodrı'guez-Cortez V, del Pino-Molina, L., Rodrı'guez-Ubreva, J., 177 Ciudad, L., Go'mez-Cabrero, D., Company, C., Urquiza, JM., Tegne'r, J., 178 Rodrı'guez-Gallego, C., Lo'pez-Granados, E., Ballestar, E. Monozygotic 179 twins discordant for common variable immunodeficiency reveal impaired DNA 180 demethylation during nai"ve-to-memory B-cell 181 transition. NATURE COMMUNICATIONS 6:7335 DOI: 101038/ncomms8335 182 |wwwnaturecom/naturecommunications. 2015.

183 14. Yong P, Orange, JS., Sullivan, KE. . Pediatric common variable 184 immunodeficiency: Immunologic and phenotypic associations with switched 185 memory B cells. Pediatr Allergy Immunol 2010;21:852-8. 